\title{
Inventory Management Based on Moving Average
}

\section{Manajemen Inventaris Berdasarkan Moving Average}

\author{
Rasyidah $^{1 *}$, Aldo Erianda ${ }^{1}$, Putri Huriati ${ }^{1}$
}

\begin{abstract}
Overstock is a problem that often occurs in inventory management, the factor are the number of sales and expired date. CV.A is a distributor company for goods. In case of inventory control at CV.A, this study compared two kind of sales forecasting system; Weighted Moving Average (WMA) and Exponential Smoothing (ES) methods. Research results showed the forecast sales for SNACK X using WMA method in July 2021 is 1662, while the ES method is 1697. After performed forecasting, the error value of the two methods was calculated. As the results, Mean Absolute Deviation (MAD) and the Mean Squared Error (MSE) of WMA are 630 and 767304, respectively. For ES the MAD and MSE value are 626 and 806949, respectively. Based on the results, WMA has a smaller error value, it can be concluded that WMA is better than the ES method.
\end{abstract}

Keywords

Inventory, stock, forecasting, moving average, MAD, MSE, MAPE

\begin{abstract}
Abstrak
Permasalahan yang sering terjadi pada manajemen persediaan adalah terjadinya kelebihan stok (overstock), faktor penyebabnya adalah banyaknya penjualan dan terbatas masa kadaluarsa. CV.A adalah sebuah perusahaan yang bergerak dibidang distributor barang. Untuk pengendalian persediaan barang pada CV.A, peneliti mengimplementasikan peramalan menggunakan metode Weighted Moving Average (WMA) dan Exponential Smoothing (ES). Dari hasil penelitian, peramalan penjualan produk SNACK X dengan metode WMA untuk bulan juli 2021 adalah sebanyak 1662, sedangkan dengan metode ES diramalkan sebanyak 1697. Setelah melakukan peramalan, kemudian dihitung nilai error dari kedua metode tersebut, sehingga didapatkan hasil Mean Absolute Deviation (MAD) dan Mean Squared Error (MSE) dari WMA masing-masing adalah 630 dan 767304, dan untuk ES nilai MAD dan MSE adalah 626 dan 806949. Jika dibandingkan kedua metode tersebut WMA memiliki nilai error lebih kecil sehingga dapat disimpulkan bahwa WMA lebih baik dibanding metode ES.
\end{abstract}

\section{Kata Kunci}

Inventaris. persediaan, peramalan, moving average, MAD, MSE, MAPE

${ }^{1}$ Information Technology Department, Politeknik Negeri Padang

Kampus Limau Manis, Padang, Indonesia

*rasyidah@pnp.ac.id

Submitted : February 13, 2022. Accepted : Februari 27, 2022. Published : February 28, 2022. 


\section{PENDAHULUAN}

Persediaan adalah salah satu unsur terpenting dalam operasi perusahaan, dimana barang yang disimpan dan kemudian digunakan kembali untuk proses produksi ataupun untuk dijual kembali [1]. Dengan adanya persediaan yang cukup, proses kegiatan jual beli dapat berjalan dengan lancar.

Manajemen persediaan adalah sistem yang berguna untuk mengelola persediaan. Bagaimana barang persediaan dapat dikelompokkan dan seberapa akurat persediaan dapat dijaga. Pada sebuah perusahaan dagang, persediaan merupakan hal yang sangat penting dalam operasi perusahaan. Persediaan harus dikelola dengan sangat baik agar tidak menggangu operasional perusahaan dalam proses jual beli [2]. Sebuah perusahaan dapat mengurangi biaya operasional dengan mengurangi persediaan, namun di sisi lain, proses jual beli dapat terganggu atau terhenti apabila stok barang tidak tersedia [3]. Manajemen Persediaan bertujuan untuk menentukan kesimbangan antara persediaan dan transaksi pelanggan, untuk mengurangi kelebihan biaya yang ditanggung oleh perusahaan dalam manajemen persediaan.

Permasalahan yang sering terjadi pada manajemen persediaan adalah resiko terjadinya kelebihan stok (overstock), faktor yang menyebabkan terjadinya overstock adalah banyaknya penjualan dan terbatas masa kadaluarsa. Manajemen persediaan menjadi sangat penting karena persediaan yang terlalu banyak (overstock) dan terjadi secara terus menerus akan mangakibatkan dead-stock karena kadaluarsa, perubahan minat atau hal lainnya [4].

Dalam melakukan analisa ekonomi atau kegiatan usaha perusahaan harus memperkirakan apa yang akan terjadi dimasa yang akan datang. Peramalan adalah salah satu cara untuk yang dapat dilakukan untuk membantu perusahaan dalam mengambil keputusan manajemen. Peramalan dapat menjadi dasar untuk perencanaan jangka pendek ataupun jangka panjang [4].

Dalam menentukan peramalan terdapat beberapa metode yang dapat digunakan salah satunya adalah metode Weigted Moving Average (WMA) dan Exponential Smoothing (ES). Pada WMA setiap data historis diberikan bobot, dimana pada data yang lebih lama akan diberikan bobot yang lebih besar, karena data paling baru adalah data yang paling relevan untuk peramalan[5]. ES adalah metode yang prosedur perbaikan terus menerus pada peramalan. ES memiliki konstanta pemulusan yang nilainya antara 0 - 1 [2].

Perusahaan CV.A yang berlokasi di Solok, Sumatera Barat adalah sebuah perusahaan yang bergerak dibidang distributor barang, produk yang didistribusikan berupa makanan, minuman kemasan dan produk-produk kebutuhan sehari-hari. Berdasarkan catatan transksi penjualan yang dicatat oleh perusahaan, perusahaan ini sudah melakukan lebih dari 10.000 kali transaksi. Dimana untuk menjaga proses jual beli tetap terlaksana, perusahaan memanfaatkan persediaan untuk mengendalikan jumlah permintaan yang tidak sulit untuk diketahui dengan pasti. Persediaan yang terlalu banyak atau tidak terkendali dapat mengakibatkan terjadinya penumpukkan barang digundang (overstock) dan lama kelamaan akan menjadi dead-stock karena kadaluarsa, usang atau tren pasar yang sudah berubah, dan hal ini dapat merugikan perusahaan.

Dari permasalahan tersebut, peneliti dapat melakukan peramalan terhadap permintaan pelanggan untuk mengendalikan persediaan, agar tidak terjadinya kelebihan stok pada gudang. Untuk pengendalian persediaan barang pada CV. A, peramalan menggunakan metode WMA dan $E S$, dimana metode ini memanfaatkan data histori masa lalu untuk memprediksi transaksi pada periode yang akan datang. Kemudian, dari 2 metode tersebut akan dilakukan perbandingan dengan mencari nilai error yang paling kecil.

\section{METODE PENELITIAN}

Bagian berikutnya adalah Metode Penelitian. Pada bagian ini menerangkan dengan singkat tentang : Metode apa yang digunakan dalam melakukan penelitian; Deskripsi singkat objek 
penelitian yang diteliti; Deskripsi singkat cara pengambilan data dan atau proses penelitian yang dilakukan.

Pada penelitian ini pendekatan yang dilakukan adalah pendekatan kuantitatif serta studi literatur dengan cara mengumpulkan informasi yang berkaitan dengan penelitian dan data yang digunakan adalah model matimatis berdasarkan data masa lalu[2]. Pendekatan Kuantitatif dibagi menjadi 2 kelompok yaitu analisis sebab akibat (causal methods) dan Analisa deret berkala (Time Series). Teknik menghitung deret berkala terbagi 3 yaitu moving average, $W M A$, dan ES [6].

Data penelitian menggunakan data penjualan produk pada CV. A yang sudah dikumpulkan dari bulan April 2020 hingga Juni 2021, data tersebut akan diuji menggunakan metode WMA 3 bulanan dan metode ES degan nilai konstanta $\alpha=0.1, \alpha=0.5$ dan $\alpha=0.9$. data tersebut dapat dilihat pada Tabel 1.

Tabel 1. Data Penjualan Produk Snack X.

\begin{tabular}{|c|l|l|}
\hline No & Periode & Terjual \\
\hline 1 & Apr-20 & 1,415 \\
\hline 2 & May-20 & 1,700 \\
\hline 3 & Jun-20 & 2,873 \\
\hline 4 & Jul-20 & 1,959 \\
\hline 5 & Aug-20 & 4,185 \\
\hline 6 & Sep-20 & 2,718 \\
\hline 7 & Oct-20 & 3,465 \\
\hline 8 & Nov-20 & 2,956 \\
\hline 9 & Dec-20 & 2,768 \\
\hline 10 & Jan-21 & 3,451 \\
\hline 11 & Feb-21 & 2,996 \\
\hline 12 & Mar-21 & 1,320 \\
\hline 13 & Apr-21 & 2,497 \\
\hline 14 & May-21 & 1,635 \\
\hline 15 & Jun-21 & 1,401 \\
\hline
\end{tabular}

\section{Metode Weigthed Moving Average}

Metode Weigthed Moving Average merupakan metode digunakan untuk menentukan trend dari suatu deret waktu. Metode $W M A$ ini cocok digunakan pada data yang berubah dari waktu ke waktu (time-series) [4]. Metode WMA lebih sensitif terhadap perubahan data, karena adanya pemberian bobot dimana periode yang baru diberi bobot lebih besar [6]. Persamaan metode WMA dinyatakan dalam bentuk rumus matematis, seperti pada persamaan 1.

$$
W M A=\frac{\Sigma\{(M)(y)\}}{\Sigma M}
$$

Keterangan:

M : Bobot untuk peramalan

y : Permintan periode ke-n

\section{Metode Exponential Smoothing}

Pada peramalan menggunakan metode Exponential Smoothing terdapat konstanta pemulusan yang dilambangkan dengan $(\alpha)$, nilai konstanta pemulusan dapat menggunakan angka antara 0 sampai dengan 1 . Nilai yang memberikan ketelitian peramalan paling tinggi adalah nilai konstanta yang paling baik [2]. Permasaan metode ES dinyatakan dalam bentuk rumus matematika pada persamaan 2 . 


$$
F_{t+1}=\alpha \cdot X_{t}+(1-\alpha) * F_{t}
$$

Keterangan:

$F_{t+1} \quad$ : Peramalan untuk periode $\mathrm{t}$

$\alpha \quad$ : faktor atau konstanta pemulusan

$X_{t} \quad$ : data permintaan pada periode ke $\mathrm{t}$

Mengukur Kesalahan Peramalan

Suatu peramalan dapat dikatakan sempurna jika nilai yang diramalkan sama dengan nilai aktual. Akan tetapi, dalam melakukan peramalan selalu tepat dan akurat sangat sulit. Untuk menghitung tingkat kesalahan peramalan, dapat dilakukan dengan menggunakan [2]:

Mean Absolute Deviation (MAD)

MAD merupakan rata-rata kesalahan mutlal selama periode tertentu tanpa memperhatikan hasil peramalan lebih besar atau kecil dari nilai aktual [7]. Rumus matematis MAD dinyatakan dalam bentuk sebagaimana tertulis di persamaan 3.

$$
M A D=\frac{\Sigma|A-F|}{n}
$$

Keterangan:

A : Nilai Aktual

F : Nilai Peramalan

$\mathrm{n}$ : Jumlah Periode peramalan

\section{Mean Square Error (MSE)}

MSE dihitung dengan menjumlahkan kuadrat semua kesalahan peramalan pada setiap periode kemudian membaginya dengan jumlah periode peramalan [7]. Rumus matematis MSE dinyatakan pada persamaan 4.

$$
M S E=\frac{\Sigma(A-F)^{2}}{n}
$$

\section{HASIL DAN PEMBAHASAN}

Untuk meramalkan persediaan barang pada periode yang akan datang yaitu periode Juli 2021, data yang digunakan adalah data penjualan April 2020 sampai Juni 2021 dari produk yang paling sering dibeli pelanggan yaitu produk SNACK X. Peramalan akan dilakukan dengan menggunakan metode WMA 3 bulanan dengan bobot 3,2,1 dan metode exponential smooting dengan nilai konstanta pemulusan 0.1, 0.5 dan 0.9 .

\section{Perhitungan Peramalan menggunakan WMA 3 bulanan}

Penjabaran cara perhitungan peramalan perencanaan persediaan untuk bulan Juli 2021 dapat dilihat pada persamaan 5 .

$$
W M A=\frac{(3 * 1654+2 * 2497+1 * 1320)}{6}=1662
$$

Dari perhitungan diatas, didapatkan hasil peramalan pada bulan Juli 2021 adalah 1662. Hasil peramalan dari histori penjualan dapat dilihat pada Tabel 2. Dan representasi grafiknya ada pada gambar 1 .

Tabel 2. Hasil Peramalan WMA 3 Bulanan

\begin{tabular}{|c|l|l|l|}
\hline No. & Periode & Terjual & WMA \\
\hline 1 & Apr-20 & 1,415 & \\
\hline 2 & May-20 & 1,700 & \\
\hline 3 & Jun-20 & 2,873 & \\
\hline 4 & Jul-20 & 1,959 & 2239 \\
\hline
\end{tabular}




\begin{tabular}{|c|l|l|l|}
\hline No. & Periode & Terjual & WMA \\
\hline 5 & Aug-20 & 4,185 & 2221 \\
\hline 6 & Sep-20 & 2,718 & 3224 \\
\hline 7 & Oct-20 & 3,465 & 3081 \\
\hline 8 & Nov-20 & 2,956 & 3336 \\
\hline 9 & Dec-20 & 2,768 & 3086 \\
\hline 10 & Jan-21 & 3,451 & 2947 \\
\hline 11 & Feb-21 & 2,996 & 3141 \\
\hline 12 & Mar-21 & 1,320 & 3110 \\
\hline 13 & Apr-21 & 2,497 & 2234 \\
\hline 14 & May-21 & 1,635 & 2188 \\
\hline 15 & Jun-21 & 1,401 & 1870 \\
\hline 16 & Jul-21 & & 1662 \\
\hline
\end{tabular}

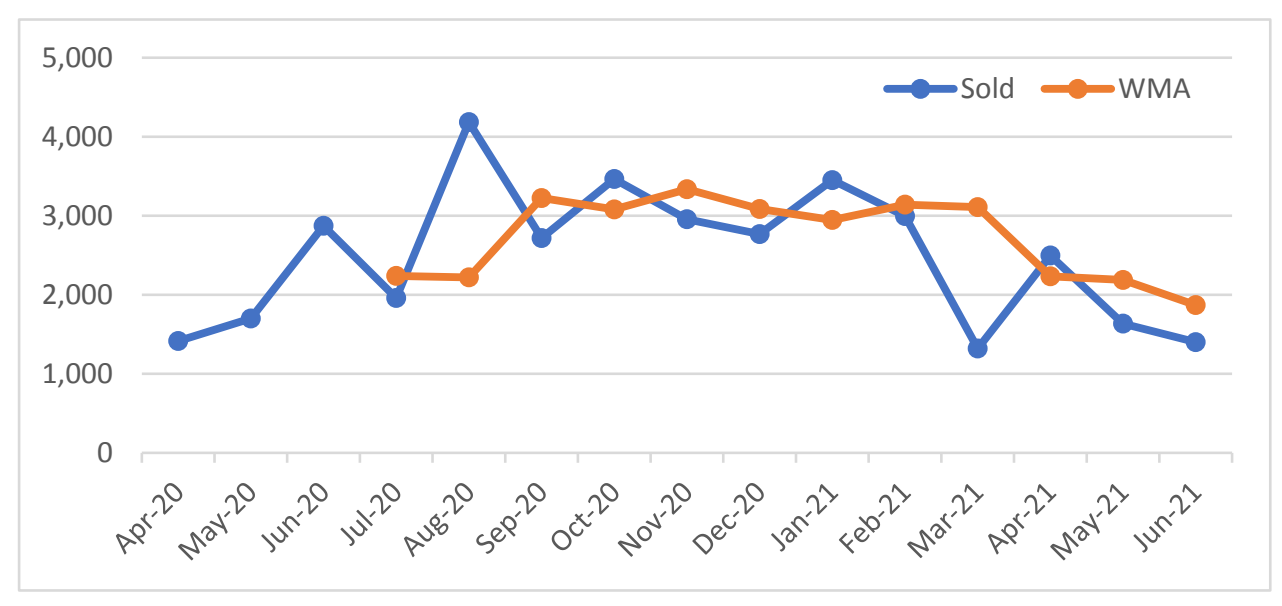

Gambar 1. Grafik peramalan menggunakan Weighted Moving Average

Setelah mendapatkan hasil peramalan, langkah selanjutnya yaitu menghitung nilai kesalahan peramalan menggunakan MAD dan MSE, dapat dilihat pada Tabel 3.

Tabel 3. Menghitung Nilai MAD, MSE

\begin{tabular}{|c|l|l|l|l|l|}
\hline No & Periode & Terjual & WMA & MAD & MSE \\
\hline 1 & Apr-20 & 1,415 & & & \\
\hline 2 & May-20 & 1,700 & & & \\
\hline 3 & Jun-20 & 2,873 & & & \\
\hline 4 & Jul-20 & 1,959 & 2239 & 280 & 78400 \\
\hline 5 & Aug-20 & 4,185 & 2221 & 1965 & 3859260 \\
\hline 6 & Sep-20 & 2,718 & 3224 & 506 & 256373 \\
\hline 7 & Oct-20 & 3,465 & 3081 & 385 & 147840 \\
\hline 8 & Nov-20 & 2,956 & 3336 & 380 & 144400 \\
\hline 9 & Dec-20 & 2,768 & 3086 & 318 & 101124 \\
\hline 10 & Jan-21 & 3,451 & 2947 & 504 & 254184 \\
\hline 11 & Feb-21 & 2,996 & 3141 & 145 & 20977 \\
\hline 12 & Mar-21 & 1,320 & 3110 & 1790 & 3202907 \\
\hline 13 & Apr-21 & 2,497 & 2234 & 263 & 69257 \\
\hline 14 & May-21 & 1,635 & 2188 & 553 & 305625 \\
\hline
\end{tabular}




\begin{tabular}{|l|l|l|l|l|l|}
\hline 15 & Jun-21 & 1,401 & 1870 & 469 & 219805 \\
\hline \multicolumn{3}{|c|}{ Total } & 7557 & 8660151 \\
\hline \multicolumn{3}{|c|}{ MAD | MSE } & 630 & 767304 \\
\hline
\end{tabular}

Berdasarkan Tabel 3 hasil perhitungan kesalahan peramalan didapatkan nilai MAD adalah 630 dan MSE adalah 767304.

\section{Perhitungan permalan menggunakan metode $E S(a=0.1)$}

Perhitungan peramalan perencanaan persediaan untuk bulan Juli 2021 dapat dilihat penjabarannya di persamaan 6.

$$
F_{\text {Juli } 2021}=0.1 * 1401+(1-0.1) * 2272=2184
$$

Dari perhitungan peramalan diatas, hasil untuk bulan juli 2021 adalah 2184. Hasil peramalan dengan metode exponential smooting dengan konstanta pemulusan 0.1 dapat dilihat pada Tabel 4.

Tabel 4. Hasil Peramalan ES $(A=0.1)$

\begin{tabular}{|c|l|l|l|}
\hline \multirow{2}{*}{ No } & \multirow{2}{*}{ Periode } & Terjual & Ramalan \\
\cline { 4 - 4 } & & & -0.1 \\
\hline 1 & Apr-20 & 1,415 & 1415 \\
\hline 2 & May-20 & 1,700 & 1415 \\
\hline 3 & Jun-20 & 2,873 & 1444 \\
\hline 4 & Jul-20 & 1,959 & 1586 \\
\hline 5 & Aug-20 & 4,185 & 1624 \\
\hline 6 & Sep-20 & 2,718 & 1880 \\
\hline 7 & Oct-20 & 3,465 & 1964 \\
\hline 8 & Nov-20 & 2,956 & 2114 \\
\hline 9 & Dec-20 & 2,768 & 2198 \\
\hline 10 & Jan-21 & 3,451 & 2255 \\
\hline 11 & Feb-21 & 2,996 & 2375 \\
\hline 12 & Mar-21 & 1,320 & 2437 \\
\hline 13 & Apr-21 & 2,497 & 2325 \\
\hline 14 & May-21 & 1,635 & 2342 \\
\hline 15 & Jun-21 & 1,401 & 2272 \\
\hline 16 & Jul-21 & & 2184 \\
\hline
\end{tabular}

Setelah mendapatkan hasil peramalan menggunakan metode $E S$ dengan $\alpha=0.1$, Langkah selanjutnya adalah menghitung nilai MAD, dan MSE untuk mengetahui nilai error peramalan. Hasil perhitungan MAD dan MSE dapat dilihat pada Tabel 5.

Tabel 5. Hasil Perhitungan Nilai MAD Dan MSE ( $A=0.1)$

\begin{tabular}{|c|l|l|l|l|l|}
\hline No & Periode & Terjual & ES & \multicolumn{1}{|c|}{ MAD } & \multicolumn{1}{|c|}{ MSE } \\
\hline 1 & Apr-20 & 1,415 & 1415 & 0 & 0 \\
\hline 2 & May-20 & 1,700 & 1415 & 285 & 81225 \\
\hline 3 & Jun-20 & 2,873 & 1444 & 1430 & 2043470 \\
\hline 4 & Jul-20 & 1,959 & 1586 & 373 & 138794 \\
\hline 5 & Aug-20 & 4,185 & 1624 & 2561 & 6560232 \\
\hline 6 & Sep-20 & 2,718 & 1880 & 838 & 702521 \\
\hline
\end{tabular}




\begin{tabular}{|c|c|c|c|c|c|}
\hline No & Periode & Terjual & ES & MAD & MSE \\
\hline 7 & Oct-20 & 3,465 & 1964 & 1501 & 2254049 \\
\hline 8 & Nov-20 & 2,956 & 2114 & 842 & 709325 \\
\hline 9 & Dec-20 & 2,768 & 2198 & 570 & 324892 \\
\hline 10 & Jan-21 & 3,451 & 2255 & 1196 & 1430400 \\
\hline 11 & Feb-21 & 2,996 & 2375 & 621 & 386131 \\
\hline 12 & Mar-21 & 1,320 & 2437 & 1117 & 1247120 \\
\hline 13 & Apr-21 & 2,497 & 2325 & 172 & 29560 \\
\hline 14 & May-21 & 1,635 & 2342 & 707 & 500222 \\
\hline 15 & Jun-21 & 1,401 & 2272 & 871 & 757835 \\
\hline \multicolumn{4}{|c|}{ Total } & 13084 & 171189204 \\
\hline \multicolumn{4}{|c|}{ MAD | MSE } & 935 & 1226127 \\
\hline
\end{tabular}

Dari perhitungan diatas, diketahui bahwa nilai MAD adalah 935 dan nilai MSE adalah 1226127.

\section{Perhitungan peramalan menggunakan metode Exponential Smooting $(\mathrm{a}=0.5)$}

Perhitungan peramalan perencanaan persediaan untuk bulan Juli 2021 dapat dihitung sebagaimana persamaan 7 .

$$
F_{\text {Juli } 2021}=0.5 * 1401+(1-0.5) * 1993=1697
$$

Dari perhitunan peramalan diatas, hasil untuk bulan Juli 2021 adalah 1697. Hasil peramalan dengan metode ES dengan konstanta pemulusan 0.5 dapat dilihat pada Tabel 6 .

Tabel 6 Hasil Peramalan ES ( $A=0.5)$

\begin{tabular}{|c|l|l|l|}
\hline No & Periode & Terjual & $\begin{array}{c}\text { Ramalan } \\
(0.5)\end{array}$ \\
\hline 1 & Apr-20 & 1,415 & 1415 \\
\hline 2 & May-20 & 1,700 & 1415 \\
\hline 3 & Jun-20 & 2,873 & 1558 \\
\hline 4 & Jul-20 & 1,959 & 2215 \\
\hline 5 & Aug-20 & 4,185 & 2087 \\
\hline 6 & Sep-20 & 2,718 & 3136 \\
\hline 7 & Oct-20 & 3,465 & 2927 \\
\hline 8 & Nov-20 & 2,956 & 3196 \\
\hline 9 & Dec-20 & 2,768 & 3076 \\
\hline 10 & Jan-21 & 3,451 & 2922 \\
\hline 11 & Feb-21 & 2,996 & 3187 \\
\hline 12 & Mar-21 & 1,320 & 3091 \\
\hline 13 & Apr-21 & 2,497 & 2206 \\
\hline 14 & May-21 & 1,635 & 2351 \\
\hline 15 & Jun-21 & 1,401 & 1993 \\
\hline 16 & Jul-21 & & 1697 \\
\hline
\end{tabular}

Setelah mendapatkan hasil peramalan menggunakan metode $E S$ dengan $\alpha=0.5$, Langkah selanjutnya adalah menghitung nilai MAD, dan MSE untuk mengetahui nilai error peramalan. Hasil perhitungan MAD dan MSE dapat dilihat pada Tabel 7.

Tabel 7. Hasil Perhitungan Nilai MAD Dan MSE (A=0.5) 


\begin{tabular}{|c|c|c|c|c|c|}
\hline No & Periode & Terjual & $\begin{array}{c}\text { Ramalan } \\
(\mathrm{a}=0.5)\end{array}$ & MAD & MSE \\
\hline 1 & Apr-20 & 1,415 & 1415 & - & - \\
\hline 2 & May-20 & 1,700 & 1415 & 285 & 81225 \\
\hline 3 & Jun-20 & 2,873 & 1558 & 1316 & 1730540 \\
\hline 4 & Jul-20 & 1,959 & 2215 & 256 & 65664 \\
\hline 5 & Aug-20 & 4,185 & 2087 & 2098 & 4401080 \\
\hline 6 & Sep-20 & 2,718 & 3136 & 418 & 174776 \\
\hline 7 & Oct-20 & 3,465 & 2927 & 538 & 289410 \\
\hline 8 & Nov-20 & 2,956 & 3196 & 240 & 57608 \\
\hline 9 & Dec-20 & 2,768 & 3076 & 308 & 94869 \\
\hline 10 & Jan-21 & 3,451 & 2922 & 529 & 279837 \\
\hline 11 & Feb-21 & 2,996 & 3187 & 191 & 36291 \\
\hline 12 & Mar-21 & 1,320 & 3091 & 1771 & 3137330 \\
\hline 13 & Apr-21 & 2,497 & 2206 & 291 & 84899 \\
\hline 14 & May-21 & 1,635 & 2351 & 716 & 513104 \\
\hline 15 & Jun-21 & 1,401 & 1993 & 592 & 350649 \\
\hline \multicolumn{4}{|c|}{ Total } & 9549 & 91188602 \\
\hline \multicolumn{4}{|c|}{ MAD | MSE } & 682 & 806949 \\
\hline
\end{tabular}

Dari perhitungan diatas, diketahui bahwa nilai MAD adalah 682 dan nilai MSE adalah 806949.

Perhitungan permalan menggunakan metode $E S(a=0.9)$

Perhitungan peramalan perencanaan persediaan untuk bulan Juli 2021 dapat dihitung sebagaimana persamaan 8 .

$$
F_{\text {Juli } 2021}=0.9 * 1401+(1-0.9) * 1711=1432
$$

Dari perhitunan peramalan diatas, hasil untuk bulan Juli 2021 adalah 1697. Hasil peramalan dengan metode $E S$ dengan konstanta pemulusan 0.9 dapat dilihat pada Tabel 8.

Tabel 8 Hasil Peramalan ES ( $A=0.9)$

\begin{tabular}{|c|l|l|l|}
\hline No & Periode & Terjual & $\begin{array}{c}\text { Ramalan } \\
(0.9)\end{array}$ \\
\hline 1 & Apr-20 & 1,415 & 1415 \\
\hline 2 & May-20 & 1,700 & 1415 \\
\hline 3 & Jun-20 & 2,873 & 1672 \\
\hline 4 & Jul-20 & 1,959 & 2753 \\
\hline 5 & Aug-20 & 4,185 & 2038 \\
\hline 6 & Sep-20 & 2,718 & 3970 \\
\hline 7 & Oct-20 & 3,465 & 2843 \\
\hline 8 & Nov-20 & 2,956 & 3403 \\
\hline 9 & Dec-20 & 2,768 & 3001 \\
\hline 10 & Jan-21 & 3,451 & 2791 \\
\hline 11 & Feb-21 & 2,996 & 3385 \\
\hline 12 & Mar-21 & 1,320 & 3035 \\
\hline 13 & Apr-21 & 2,497 & 1491 \\
\hline 14 & May-21 & 1,635 & 2396 \\
\hline
\end{tabular}




\begin{tabular}{|l|l|l|l|}
15 & Jun-21 & 1,401 & 1711 \\
\hline 16 & Jul-21 & & 1432 \\
\hline
\end{tabular}

Setelah mendapatkan hasil peramalan menggunakan metode $E S$ dengan $\alpha=0.9$, Langkah selanjutnya adalah menghitung nilai MAD, dan MSE untuk mengetahui nilai error peramalan. Hasil perhitungan MAD dan MSE dapat dilihat pada Tabel 9.

Tabel 9 Hasil Perhitungan Nilai MAD Dan MSE (A=0.9)

\begin{tabular}{|c|c|c|c|c|c|c|}
\hline No & Periode & Terjual & ES & \multicolumn{2}{|c|}{ MAD } & MSE \\
\hline 1 & Apr-20 & 1,415 & 1415 & \multicolumn{2}{|l|}{0} & 0 \\
\hline 2 & May-20 & 1,700 & 1415 & \multicolumn{2}{|c|}{285} & 81225 \\
\hline 3 & Jun-20 & 2,873 & 1672 & \multicolumn{2}{|c|}{1202} & 1443602 \\
\hline 4 & Jul-20 & 1,959 & 2753 & \multicolumn{2}{|c|}{794} & 630198 \\
\hline 5 & Aug-20 & 4,185 & 2038 & \multicolumn{2}{|c|}{2147} & 4607956 \\
\hline 6 & Sep-20 & 2,718 & 3970 & \multicolumn{2}{|c|}{1252} & 1568352 \\
\hline 7 & Oct-20 & 3,465 & 2843 & \multicolumn{2}{|c|}{622} & 386593 \\
\hline 8 & Nov-20 & 2,956 & 3403 & \multicolumn{2}{|l|}{447} & 199651 \\
\hline 9 & Dec-20 & 2,768 & 3001 & \multicolumn{2}{|l|}{233} & 54141 \\
\hline 10 & Jan-21 & 3,451 & 2791 & \multicolumn{2}{|l|}{660} & 435246 \\
\hline 11 & Feb-21 & 2,996 & 3385 & \multicolumn{2}{|l|}{389} & 151342 \\
\hline 12 & Mar-21 & 1,320 & 3035 & \multicolumn{2}{|c|}{1715} & 2940891 \\
\hline 13 & Apr-21 & 2,497 & 1491 & \multicolumn{2}{|c|}{1006} & 1011050 \\
\hline 14 & May-21 & 1,635 & 2396 & \multicolumn{2}{|l|}{761} & 579805 \\
\hline 15 & Jun-21 & 1,401 & 1711 & \multicolumn{2}{|l|}{310} & 96190 \\
\hline \multicolumn{5}{|c|}{ Total } & 11821 & 139744087 \\
\hline \multicolumn{4}{|c|}{ MAD | MSE } & & 844 & 1013303 \\
\hline
\end{tabular}

Dari perhitungan diatas, diketahui bahwa nilai MAD adalah 844 dan nilai MSE adalah 1013303.

\section{Hasil perhitungan}

Hasil perhitungan peramalan persediaan pada bulan Juli 2021 menggunakan metode $W M A$ adalah 1662 untuk produk SNACK X, sedangkan untuk peramalan yang menggunakan metode ES dengan $\alpha=0.1$ hasil peramalannya adalah 2184 untuk produk yang sama, $\alpha=0.5$ hasil peramalannya 1697 dan $\alpha=0.9$ hasil peramalannya 1432 .

Berdasarkan hasil peramalan yang dipadapatkan dari kedua metode tersebut, Langkah yang dilakukan selanjutnya adalah menghitung kesalahan peramalan dari kedua metode tersebut, dan didapatkan untuk metode WMA nilai MAD adalah 630 dan MSE adalah 767304. Sedangkan nilai kesalahan peramalan dari metode $E S$ dengan $\alpha=0.1$ didapatkan nilai MAD adalah 935 dan MSE adalah 1226127, $\alpha=0.5$ didapatkan nilai MAD adalah 682 dan MSE adalah 806949, dan $\alpha=0.9$ didapatkan nilai MAD adalah 844 dan MSE adalah 1013303. Maka dapat disimpulkan bahwa dari perbandingan kedua metode tersebut metode WMA lebih baik dari pada metode $E S$ untuk peramalan persediaan produk SNACK X.

\section{SIMPULAN DAN SARAN}

\section{Simpulan}

Berdasarkan penelitian yang sudah dilakukan, dapat disimpulan bahwa peramalan persediaan barang dapat membantu perusahaan untuk mengontrol persediaan agat tidak terjadi kelibihan stok yang dapat mengakibatkan bertambahnya biaya yang harus dikeluarkan 
oleh perusahaan. Setelah melakukan peramalan menggunakan 2 metode yang berbeda yaitu metode $W M A$ dan $E S$, dapat diambil kesimpulan bahwa metode $W M A$ lebih baik dari pada metode ES karena memiliki nilai error lebih kecil.

\section{Saran}

Untuk penelitian yang akan dating, disarankan untuk menggunakan metode lain untuk mendapatkan hasil peramalan yang lebih akurat lagi, seperti menggunakan metode Double Moving Average dan Double Exponential Smoothing.

\section{DAFTAR RUJUKAN}

[1] C. A. Suhendra, M. Asfi, W. J. Lestari, and I. Syafrinal, "Sistem Peramalan Persediaan Sparepart Menggunakan Metode Weight Moving Average dan Reorder Point Forecasting System for Spare Parts Inventory Using the Weight Moving Average and Reorder Point Methods," vol. 20, no. 2, pp. 343-354, 2021.

[2] M. . Fina Andika Frida Astuti, S.T. and M. . Arif Rochman Fachrudin, S.T., MANAJEMEN NDUSTRI. Klaten, Jawa Tengah: Lakeisha, 2020.

[3] R. Vikaliana, Y. Sofian, N. Solihati, D. B. Adji, and S. S. Maulia, MANAJEMEN PERSEDIAAN. Bandung: CV. MEDIA SAINS INDONESIA, 2020.

[4] F. R. Giarti et al., "Sistem Prediksi Menggunakan Metode Weighted Moving Average Untuk Penentuan Jumlah Order Barang," vol. 16, no. 2, pp. 37-42, 2017.

[5] Z. Silvya, A. Zakir, D. Irwan, P. Studi, S. Informasi, and U. H. Medan, "PENERAPAN METODE WEIGHTED MOVING AVERAGE UNTUK PERAMALAN,” vol. 8, no. 2, pp. 59-64, 2020.

[6] R. Y. Hayuningtyas and T. Informatika, "PERAMALAN PERSEDIAAN BARANG MENGGUNAKAN METODE WEIGHTED MOVING AVERAGE DAN METODE DOUBLE EXPONENTIAL," vol. 13, no. 2, pp. 217-222, 2017.

[7] M. Average and E. Smoothing, "PERAMALAN PERMINTAAN PAVING MENGGUNAKAN METODE," vol. 03, no. 01, pp. 14-18, 2021. 